\section{Tückische Shiitake-Pilze}

N it dem Einzug japanischer Gerichte in Europa sollte man sich auch mit deren potenziellen Gesundheitsrisiken vertraut machen. Gefahren lauern vor allem in ungegarten Zutaten, die z.B. Toxine enthalten können - so der Fall in Shiitake-Pilzen (Lentinus edodes). Der Pilz enthält Lentinan, ein Polysaccharid, das die in Ostasien gut bekannte ShiitakeDermatitis auslöst. Diese nicht allergische Hauterkrankung zeigt ein charakteristisches klinisches Bild mit linear angeordneten Gruppen von erythematösen Papeln am Rumpf und obligatem Juckreiz. In Zweifelsfällen sichert ein oraler Provokationstest die Diagnose. So konnte auch einem 37-jährigen Hobbykoch aus London geholfen werden, der nach dem Genuss größerer Mengen roher Shiitake-Pil-

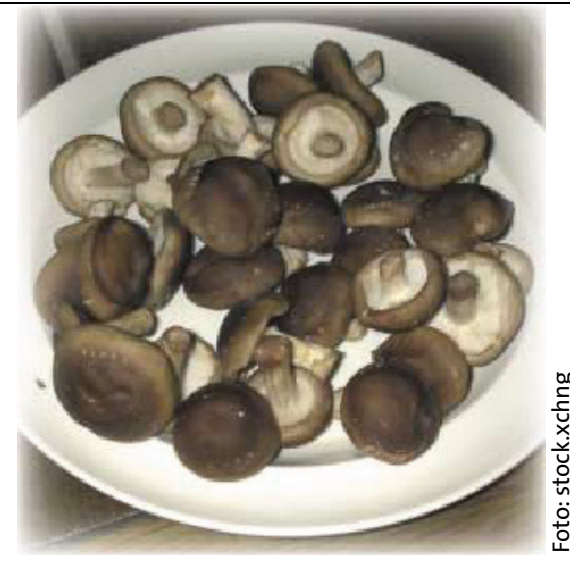

ze die typischen streifenförmigen Läsionen auf der Brust aufwies, die sich auf Arme, Beine und Gesicht ausbreiteten. Die Läsionen verschwanden innerhalb von einer Woche und ließen sich durch den Verzehr roher Shiitake-Pilze erneut provozieren. Da Lentinan thermolabil ist, geht von gekochten Pilzen keine Gefahr aus. $\quad j l p$

Mak RKH et al. Br J Dermatol 2006; 154:

800-1

\title{
Müßiger Kampf gegen Mobilfunkmast
}

\begin{abstract}
Cit 1999 war auf dem Dach eines Mietshauses eine Mobilfunksendeanlage installiert. Dafür kassierte der Hauseigentümer von der Betreibergesellschaft Nutzungsentgelt. Der Mieter der Wohnung im Dachgeschoss sah dadurch seine Gesundheit gefährdet, war er doch ohnedies schon bettlägerig und auf einen Herzschrittmacher angewiesen. Beim Bundesgerichtshof scheiterte jedoch seine Klage auf Beseitigung der Antenne: Laut allen Gutachten liege die Beeinträchtigung durch die elektromagnetischen Felder der Anlage innerhalb der geltenden Grenz-
\end{abstract}

werte (Bundesimmissionsschutzverordnung). Der Herzschrittmacher werde von ihnen nicht gestört. Vermieter müssten die geltenden Grenzwerte einhalten, mehr nicht. Dass die wissenschaftliche Diskussion über die von Mobilfunksendeanlagen ausgehenden Gefahren andauere, sei zwar richtig, aber die festgelegten Grenzwerte beruhten auf den übereinstimmenden Empfehlungen von Sachverständigengremien, die sich an nachweisbaren Gesundheitsgefahren orientierten.

gri

Bundesgerichtshof, VIII ZR 74/O5

\section{Morgendliche Badezimmer-Rhinitis}

eden Morgen, wenn ich mich im Badezimmer aufhalte, muss ich plötzlich husten und mir läuft die Nase“, mit dieser seit rund einem Jahr bestehenden Symptomatik stellte sich eine ansonsten gesunde 20-Jährige in einer italienischen Allergologieambulanz vor. Der Pricktest war positiv auf Hausstaubmilben und Kompositen. Beim Durchgehen einer Liste mit gängigen Korbblütlern hatte die Patientin gleich die richtige Eingebung: Seit rund einem Jahr benutzte die
Familie ein neues Toilettenpapier, das einen angenehmen Kamillenduft verströmte. Pricktest und Nachweis von spezifischem Serum-IgE auf Kamille waren positiv, ebenso ein Expositionsversuch mit dem Toilettenpapier. Nach Entfernen der vermuteten Allergenquelle an der Toilette verschwanden tatsächlich auch die Symptome.

bk

Scala G. Int Arch Allergy Immunol 2006; 139:330-1

\section{Asthma ist oft COPD}

ffenbar wird eine große Zahl von Patienten mit chronischer obstruktiver Lungenerkrankung (COPD) fälschlicherweise wegen eines Asthmas behandelt. $\mathrm{Zu}$ diesem Ergebnis kommt eine Studie an rund 600 schottischen und USamerikanischen Patienten, die wegen Lungenerkrankungen in Behandlung waren. Mittels Spirometrie wurde bei 235 von ihnen eine COPD diagnostiziert. Die Hälfte dieser Patienten hatte bis dato aber nur eine Asthmadiagnose erhalten und nicht einmal $40 \%$ waren korrekt als COPD-Patienten erkannt worden. de

Tinkelman DG et al. J Asthma 2006; 43: 75-80

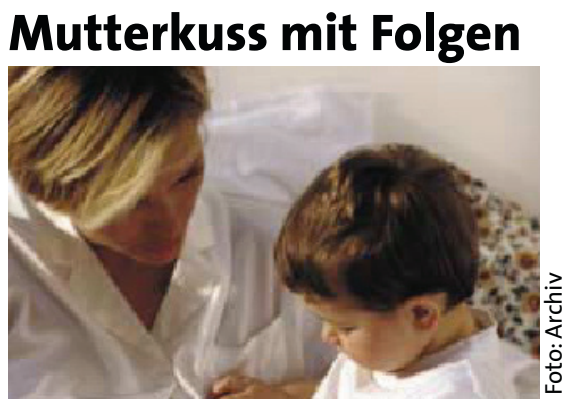

urch einen Kuss ausgelöste allergische Reaktionen sind gar nicht so selten und meist auf Lebensmittel zurückzuführen, die der nicht allergische Kusspartner vor dem Lippenkontakt konsumiert hat. Doch auch Patienten mit Arzeimittelallergie sollten ihre Emotionen kontrollieren können, wie der Fall einer italienischen Mutter zeigt, bei der unmittelbar nach dem Küssen ihres fünfjährigen Sohnes die Lippen anschwollen und sich im Gesicht und an den Armen ein Ausschlag zeigte. In den nächsten Tagen entwickelte die Frau auch noch perioral eine Dermatitis. Des Rätsels Lösung: Der Junge stand unter einer Antibiotikatherapie und hatte drei Stunden vor dem Kuss eine Amoxicillin-Tablette erhalten. Bereits die geringen Amoxicillin-Konzentrationen im Speichel des Kindes waren offensichtlich ausreichend, um bei der Mutter Symptome auszulösen.

Mancuso G et al. Contact Dermatitis 2006; 54: 226 